\title{
Aspects About Science in the Context of Production and Communication of Knowledge of COVID-19
}

\author{
Poliana Maia $^{1}$ (D) Rosária Justi ${ }^{2}$ : Monique Santos ${ }^{3}$ (D) \\ Accepted: 9 April 2021 / Published online: 20 April 2021 \\ (c) The Author(s), under exclusive licence to Springer Nature B.V. 2021
}

\begin{abstract}
In the context of the COVID-19 pandemic, and given the huge volume of information available for the general population (being part of them fake news), there is a clear need to foster people's understanding of the meaning of science, of how scientific knowledge is produced, communicated, and used. As one of the main aims of science education is the promotion of students' scientific literacy, one of the issues focused on teaching should be aspects of nature of science (NOS) - which can be introduced from discussions in socioscientific contexts. In this paper, we analyse the context of the COVID-19 pandemic in order to identify and discuss aspects of NOS involved in the production and communication of knowledge about it. We analyse selected scientific publications and reports from the general media, mainly focused on three broad topics about the production and validation of knowledge: (i) the characterisation of the virus, and (ii) the treatments and vaccines for COVID-19, and (iii) the communication of knowledge produced from the characterisation of scientific literature itself in the pandemic period. The analysis was carried out from a model that presents a broad and complex view of science, as it addresses several areas of knowledge and specific aspects of each of them and proposes the generation of one's view of science from an integration of some of its distinct areas and/or aspects. The results show the current pandemic is a rich socioscientific context whose discussion of social, political, economic, and ethical aspects may support students' learning of nature of science, thus fostering scientific literacy.
\end{abstract}

\section{Introduction}

Due to the pandemic caused by the coronavirus SARS-CoV-2, science has brought hope to many people around the world. At this time of uncertainty and insecurity, the media has made human attention focus on scientists and their research. The volume of information thus conveyed - often divergent - has grown by the day, which has led people to show

Rosária Justi

rjusti@ufmg.br; rjustiufmg@gmail.com

1 Instituto de Ciências Exatas e Tecnológicas, Universidade Federal de Viçosa, Campus Florestal, Florestal, Brazil

2 Instituto de Ciências Exatas, Universidade Federal de Minas Gerais, Belo Horizonte, Brazil

3 Faculdade de Educação, Universidade Federal de Minas Gerais, Belo Horizonte, Brazil 
doubts about which information should be taken into consideration. There is therefore a need for the general population to understand science, formerly distant and intangible. This means broadening people's views about its meanings, its essential characteristics, and how it develops and is validated. This is in order to prevent the creation and spread of limited and/or mistaken views and also to avoid propagation of pseudoscientific information.

Through full-time coverage of the current pandemic in various newspapers and other media, society can now access the science under construction (Latour, 1987) process more closely. In such a process, studies related to the pandemic have been carried out rapidly due to the convergence of interests of society at large. The results obtained so far have been used to support positions of governments, health agencies, and even citizens in their daily actions. On the other hand, people have often not thought about the reliability of the sources and/or the accuracy of the information received.

In general, people have access to research into the coronavirus pandemic through the media, thereby making the pandemic better understood by the general population by means of clippings, simplifications, and adaptations of information (Höttecke \& Allchin, 2020). These clippings are essential to avoid excessively scientific or detailed language, for example. However, in the current context, it is important to try to understand any bias, possible distortions, and misinformation that may be lurking behind some news, especially, but not exclusively, those published in free media, such as social networks, blogs, and videosharing websites, among others, places where anyone, whether an expert or not, can post opinions or (mis)information. According to Höttecke and Allchin (2020), individuals rely on social media as their main source of scientific information, this being due to cultural changes. This is a cause for concern because this is where fake news is often broadcast and spread. In the light of this, science education needs to (and should) play a crucial role as part of citizenship education.

In this regard, understanding the credibility of the sources, the partiality of the results, and the status of the information conveyed (that is, to what extent the information constitutes knowledge that is peer-validated and accepted, as such being considered scientific), among many other aspects, has the potential to get people involved in a thought on aspects of nature of science (NOS) integrated into a reality involving contemporary socioscientific issues.

One of the main aims of science education is the promotion of students' scientific literacy, in other words, to foster the development and mobilisation of knowledge and critical thinking as necessary for these to act in specific contexts. In this regard, the introduction of aspects of NOS into teaching is widely considered essential for the promotion and attainment of scientific literacy (see, for example, Hodson, 2014; Roberts, 2007; Hanuscin et al., 2006; Allchin, 2011). This is because citizens' scientific literacy (or lack thereof) helps to establish how they select and analyse information, how a given piece of information is used to back up their thoughts, their positions, and possibly even some of their actions (Loughran, 2011; Roberts, 2007).

Unfortunately, a lack of scientific literacy - which also includes immediacy, the willingness to want answers quickly - has resulted in citizens relying largely on fake news and other (mis)information to decide how to act, which has brought disastrous consequences. For example, in Iran, news posted on social media stating that the ingestion of methanol would be effective for tackling the coronavirus SARS-CoV-2 led many Iranians to ingest the poisonous substance, causing over 300 deaths, as well as thousands more taken ill (Karimi \& Gambrell, 2020). This sad example shows the effects of the absence of critical reading of information, questions about its source, and analytical evaluation of its reliability and accuracy, thus emphasising that the promotion of citizens' scientific literacy is 
indeed extremely necessary and relevant, within the scenario marked by the current pandemic. For this, it does not suffice just to understand aspects of NOS, since this is not the only factor that interferes with citizens' positions and actions. However, such knowledge can provide more critical and more conscientious thoughts about issues involving science.

The perspective of addressing the process of constructing scientific knowledge in the context of the pandemic from a holistic view of science is consistent with the complexity of this context, and this raises several associated socioscientific issues. Thus, the use of socioscientific contexts in science education, especially those more prominent in society and those related to the pandemic, is directly linked to the promotion of functional scientific literacy, in which the focus is on the knowledge of and about science as necessary for individuals to act in different contexts, "to engage critically with science" (Ryder, 2001, p.36). This idea is in line with the studies of Sadler et al. (2004), which emphasise the need to effectively integrate NOS and socioscientific issues in science education to promote scientific literacy, once the analysis of elements of NOS in socioscientific contexts is grounded on the construction of situational learning. In this style of learning, distinct pieces of knowledge are developed and integrated, to the point where one has to judge, position themselves, decide and/or act.

Thus, discussing events related to the context of the current pandemic presents itself as an opportunity to discuss aspects of NOS in an explicit and contextualised manner (as advocated, for instance, by Allchin, 2011; Capps \& Crawford, 2013). Such an approach may help students to develop adequate understanding of the situation and its context while also acting responsibly as critical-reflective citizens.

Based on a context similar to that proposed in this paper, Wong et al. (2009) also stress the importance of working with socioscientific issues, pointing out the potential of the involvement of students in thinking about significant yet controversial contemporary issues - which may contribute to the understanding of paths and processes of science, and their interactions with different contexts, and may help to shed light on aspects of history, philosophy, and sociology of science. These authors carried out a study on aspects of NOS related to the context of the 2002-2003 epidemic caused by the coronavirus SARS-CoV. In their study, several aspects of NOS as yet little explored in science curricula were emphasised. In reports and interviews with scientists involved in research into that epidemic, the authors had vivid examples that could be used to present and discuss several aspects, such as:

the need to combine and coordinate expertise in a number of scientific fields, the intense competition between research groups (suspended during the SARS crisis), the significance of affective issues relating to intellectual honesty and the courage to challenge authority, the pressure of funding issues on the conduct of research and the 'peace of mind' of researchers. (Wong et al., 2009, p. 108)

Subsequently, these were used to favour the development of teachers' knowledge in a continuing education course, a context in which it became evident that the theme contributed to teachers reflecting on the multiple interactions within in the process of construction of science (Wong et al., 2011). In the same vein, the current study presents an analysis of NOS aspects related to the context of the COVID-19 pandemic, as a way of both promoting reflections on an authentic context and its relationships with epistemic practices and furthering future teaching approaches involving this very context aiming at improving students' scientific literacy and knowledge of NOS.

Considering (i) the potential of the approach of a rich contemporary and prominent context in society for discussion of aspects of NOS and as a way to enhance 
teachers' knowledge of NOS (Wong et al., 2009, 2011), and (ii) the contributions of teaching approaches based on socioscientific contexts to promote the development of students' knowledge of NOS and scientific literacy (Aikenhead, 2006; Allchin, 2011, 2014; Hodson, 2014; Höttecke \& Allchin, 2020; Ryder, 2001; Sadler, 2011; Zeidler \& Nichols, 2009), this paper analyses the context of the SARS-CoV-2 pandemic to identify and promote thoughts on aspects of NOS involved in it.

This approach is justified by the current and social breadth of the theme, as global attention has been focused on the control of the pandemic or its consequences in several sectors of society. Thus, within this rich context of scientific outcomes, and their coverage by the various media, we identified an opportunity to implement a proper look at this context by the area of science education. In so doing, and by considering aspects related to science itself, we intend to analyse the complexity of the relationships involved in the production of scientific knowledge. With this in mind, we present an analysis of aspects of NOS as identified in this context, and of how these aspects are related to the socioscientific issues inherent to it.

\section{A Model for Understanding Nature of Science}

Considering our purpose of systematically analysing aspects of NOS in the context of production and dissemination of knowledge about the pandemic caused by the SARS-CoV-2, we chose to use the second version of the Model of Science for Science Education (MoSSE v.2), as proposed by Santos et al. (2020) from an initial version drawn up by Justi and Erduran (2015). Just like the original model, the MoSSE v.2 is based on two premises: (i) science is a complex cognitive, epistemic, and social activity that can and has been characterised based on different areas of knowledge, and (ii) scientific claims should be based on evidence from different areas of knowledge so that science teaching may favour the development of an authentic and broader view of science (Justi \& Erduran, 2015).

The MoSSE v. 2 was created from the integration of new perspectives to the original model, changing the scientific disciplinary perspectives initially considered and detailing their characteristic aspects to enable a better understanding of the processes involved in the construction of scientific knowledge.

Like the previous version, the MoSSE v. 2 was devised with the main purpose of supporting teachers to introduce aspects of NOS in teaching. It presents a broad and complex view of science, as it addresses several areas of knowledge (such as philosophy, psychology, anthropology, sociology, economics, and history of science) as well as specific aspects of each of them linked to science. Thus, each aspect represents distinct views on science in that area of knowledge, and these can be highlighted separately or together, depending on the focus of the analysis. However, achieving a broad view of science also depends on another essential characteristic of this model: the proposed integration between the areas. According to the MoSSE v.2, considering the scholastic context, it is initially possible to focus the analysis of an event or scientific knowledge from a given area, or from some aspect(s) within a given area. However, for students to effectively develop a broad view about science, it is also essential to focus the discussion on other areas and aspects and to make possible relationships between them explicit. In addition, although some areas have been highlighted, the model considers the possibility of integrating new areas of knowledge or new aspects of the areas currently emphasised in specific contexts. 
Seeking to contribute to the readers' understanding, we now present a brief characterisation of each area of knowledge as represented in the MoSSE v.2 (Santos et al., 2020) and the list of the main aspects identified as related to each of these (in italics throughout the text). In some cases, when the meaning of the aspect could be interpreted in several different ways or be unclear to the reader, we shall present a brief comment on it.

- Philosophy of Science: This area studies the very meaning of science by investigating, for instance, issues related to the origin, purposes, and nature of scientific knowledge, as well as ethical and moral values and any criteria necessary for the construction of scientific knowledge and of science as a whole. It includes aspects such as (i) epistemology; (ii) ethics, which discusses the ethical and moral values that guide scientific and/or epistemic practices; and (iii) logic, which involves the sequences of scientific thoughts.

- Psychology of Science: It studies the mental processes and behaviour of a scientist and, therefore, covers his/her intrapersonal relations with the processes of production and use of scientific knowledge. It also covers aspects related to his/her personal characteristics in the construction of knowledge, including (i) complexity of knowledge produced by the scientist; (ii) creativity; (iii) fallibility, related to how the scientist becomes aware of errors and deals with them; (iv) uncertainty in the process of construction of knowledge, and how the scientist deals with it; (v) motivational influence on the scientist's work; (vi) intelligence, related to the influence of the intellectual characteristics of the scientist on the production of knowledge; (vii) limitations present in the scientist's work and how he/she deals with them; (viii) nonlinearity of reasoning, meaning that there may be a resumption or abandonment of ideas; (ix) objectivity, related to the focus on a given goal; (x) the personality of the scientist; (xi) rationality, associated with the specific scientific methods and processes employed by the scientist; (xii) representation, which relates to the scientist's ability to express his/her ideas; and (xiii) subjectivity, which is the influence of each scientist's conceptions and knowledge on the construction of knowledge.

- Anthropology of Science: This area considers that the production of scientific knowledge is a kind of social action and that its development is a kind of cultural production. Therefore, it encompasses aspects such as (i) cultural influence on or by a given item of scientific knowledge and (ii) incommensurability, which addresses the dependence of the value of a given knowledge on culture.

- Sociology of Science: This area looks at how the process of production of scientific knowledge occurs, considering scientists in society, showing that science is a social practice. It involves aspects such as (i) acceptability of scientific knowledge in the scientific community; (ii) credibility of scientists, institutions, and science itself vis-à-vis the scientific community and/or the society as a whole; (iii) fallibility, associated with how scientists, in a social perspective, deal with errors in the process of knowledge construction; (iv) uncertainty, in terms of how scientists, in a social perspective, deal with uncertainties during the process of knowledge construction; (v) sociopolitical influence, related to both how science influences society and how society is influenced by science; and (vi) interactions among scientists, which involve relationships between scientists, or groups of scientists, in the process of knowledge construction.

- Economics of Science: It studies the effects of commodification (transformation of scientific knowledge into merchandise) and commercialisation (availability of scientific knowledge for sale) of scientific knowledge in its stages of production and application. It encompasses aspects such as (i) access to knowledge, associated with its mon- 
etary valuation and accessibility to it in economic terms; (ii) applicability, which discusses the interests associated with the use of a given knowledge; (iii) competitiveness between scientists and/or institutions; (iv) funding source for scientific research; (v) economic investment in research, which is tied to its results as also on social, political, environmental factors, among others; (vi) productivity, related to interest in making a profit from a given scientific study; (vii) advertising, associated with greater visibility and recognition of a given scientific study so that this increases profits; and (viii) feasibility, associated with the evaluation to define and/or justify investments in scientific research.

- History of Science: This area studies the development of scientific knowledge over time, covering aspects such as (i) historical influence, which includes the influence of historical contexts on science, and vice versa; (ii) multiplicity, which comprises the various narratives of, and/or different interpretations for, a given historical episode of science; (iii) nonlinearity, which encompasses the rescue of ideas, multiple paths, unforeseen events, and changes in the development of scientific knowledge; (iv) progressivity, which relates to the gradual and procedural development of science; and (v) tentativeness of scientific knowledge, in terms of knowledge being changed over time.

As highlighted in its original publication,

this is not just a list of tenets (...) it is aligned with a viewpoint based on wide-scope and contemporary science, like the models presented by Allchin (based on the idea of Whole Science) and by Irzik and Nola, and Erduran and Dagher (based on the idea of Family Resemblance, proposed by Wittgenstein). Our proposal going beyond these, in an attempt to characterise a viewpoint to instrumentalise teachers to think of science as a whole, attempting to guide understanding and reflections about its construction processes. (Santos et al., 2020, p. 642-643)

So, the target audience of the model are science teachers who, from understanding how distinct aspects of NOS characterise science and possible interplays between some aspects, may plan teaching activities and/or specific discussions (not based on the mere identification of the aspects) to support students' broader and more authentic views of science.

The organisation of these areas and aspects in a model in which they are integrated (as proposed in Santos et al., 2020) contributes to a broad analysis of (socio)scientific contexts. It is therefore suitable for the analysis of complex relationships between aspects of NOS in real contexts, which involve contemporary processes of production and dissemination of scientific knowledge, and where multiple influences of several types can be observed.

\section{Analytical Approaches}

Considering the swift pace of scientific production related to the current pandemic, as well as the wide publicity that the media has made about such studies, in this paper, we analyse aspects of NOS related to the processes of construction, validation, and communication of knowledge produced in the period, bearing in mind several contexts related to such processes. However, we do emphasise that we do not intend to cover the entire analysis of aspects of NOS in the current context of the pandemic, which would certainly be a reductionist approach. 
For analysis of the aspects of NOS, we have selected publications (scientific ones and also some from the general media) focused mainly on: (i) the search for information about the problem, that is, to the production and validation of knowledge about the characterisation of the virus (its origin, mapping of its genome and replication, and to the forms and control of dispersion of the pandemic); (ii) the search for solutions to the problem, which means the production and validation of knowledge related to treatments and vaccines for COVID-19; and (iii) the dissemination of knowledge produced from the characterisation of scientific literature itself in the pandemic period. These three themes were selected because we realised that they have been the most prominent in the press, which is justified by the very interest of society in relation to the need to understand the disease itself and the processes of contamination in order to adopt mitigation measures.

Even restricting the analysis to these three broad themes, the plentiful literature related to the pandemic makes it impossible to analyse everything that has been produced and publicised since the beginning of 2020. Moreover, this paper is not intended to present a review of the literature in this context. Thus, the criteria for selecting the publications were that they show examples of the diversity of socioscientific issues that permeate the context and, at the same time, enable the analysis of different aspects of NOS, allowing the characterisation of the complexity of the relationships involved in the production of scientific knowledge.

Initially, the access to the publications was made by consulting the websites of the World Health Organization (WHO) (because it is an official organisation competent to provide information on the subject) and journals Science, Nature, and The Lancet (these being respected vehicles of communication of scientific knowledge in which many academic papers were published quickly). At the same time, we accessed reports published in mainstream newspapers in the UK, the USA, and Brazil (because they are published in languages that we master, and also bring both detailed reports and interviews with scientists involved in studies published in scientific journals; in other words, they publish the knowledge produced and/or under discussion in a way that is more accessible to society in general). Finally, in all the publications we have read, we have identified references mentioned as sources of information that seemed interesting to us, and then, we read them. All publications were read between April and September 2020.

For analysing the aspects of NOS, we used the MoSSE v.2 (Santos et al., 2020) as an analytical tool. This was done because this model is in alignment with a more contemporary and broader perspective of science education, which covers its various contexts and relationships in a dynamic and integrated way, as science itself. As previously highlighted, this model presents several areas of science and related aspects, properly characterised. It also proposed that a broad view of NOS is reached by integrating aspects both from a given area and from distinct areas of science. Therefore, when using it as an analytical tool, each of the aspects was taken as a category of analysis; that is, we identified which aspect(s) might be associated to a given event, as well as how the aspect was presented in it. Thus, the integration of aspects proposed in the model was achieved by highlighting the diversity of aspects as identified in the general analysis; the fact that several aspects (related to one or more areas) can be linked simultaneously with a given event or knowledge; and the fact that such aspects often influence each other.

Each of the authors read the publications and identified all aspects presented in them. Next, individual analyses were checked, and a few discrepancies were discussed. Then, we selected representative examples to be included in this paper and discussed both how they express specific aspects of science and how they are related to each other. The analysis of 
such examples was submitted to another researcher who has extensive knowledge of the MoSSE v. 2 to ensure the reliability of the analysis. Finally, the material resulting from this process was organised as presented in the next section, in which we also relate the previous discussions to possible understandings of and about science.

\section{Results and Discussions}

\subsection{Understanding the Problem: Studies on the Structure, Reproduction, and Dispersion of SARS-CoV-2}

Since the beginning of the pandemic, the mobilisation of the scientific community has taken place on several research fronts, aiming at building and integrating knowledge to understand several aspects about the disease and its cause. Initially, identifying the SARS$\mathrm{CoV}-2$ virus, as also its genetic code, possible origins, chemical structures that compose it, and the ways they interact with each other, was essential for the research studies that followed.

Especially with regard to replication, deciphering its mechanism is crucial to develop effective preventive and therapeutic strategies (Kumar et al., 2020). From the knowledge about the genetics of the virus, it is possible, for example, to map its origin and identify the sources of its transmission to humans, which can help to prevent the contagion of this zoonosis and of other viruses that may still arise and/or undergo mutations and recombinations. Some researchers (Lu et al., 2020; Wu et al., 2020; Zhou et al., 2020) have identified a close similarity between the genetic sequencing of SARS-CoV-2 ${ }^{1}$ and other coronaviruses identified in bats. However, bats are rare in China's markets and, therefore, a hypothesis that has come to be considered as probable is that an intermediate host has played some role in the transmission. Thus, genetic sequencing data points to bats as the original hosts of the virus, which may have spread to other animals and then reached humans (by contact with animals in the Wuhan market). The three articles mentioned in this paragraph were submitted and published very close to each other (the first on 29 January, and the other two on 3 February) and were produced by a total of 78 scientists from 20 research centres or collaborating institutions. These facts prove the great involvement of the scientific community with studies related to the origin of the virus and, at the same time, the concurrent carrying out of studies with similar aims. This is an important aspect in science because one study can help to corroborate the results of another (the progressivity aspect), which increases the acceptance of their findings and, consequently, contributes to the validation of the constructed knowledge (the acceptability aspect).

Other scientists analysed the genes of different types of coronavirus from an animal called the pangolin, ${ }^{2}$ finding an expressive match between the sequences of such viruses and those of SARS-CoV-2 (Lam et al., 2020). However, the authors discuss the impossibility of establishing conclusive relationships between pangolins and the pandemic caused by SARS-CoV-2 due to discrepancies between the analysed samples. The relationship between SARS-CoV-2 and strains of coronavirus found in pangolins was also studied by

\footnotetext{
1 Isolated from epithelial cells of the respiratory system of the first infected person hospitalised in Wuhan.

2 A wild animal found in Asia and Africa, whose meat is considered a gastronomic delicacy and whose scales are used in traditional Chinese medicine (Nuwer, 2020). This animal was studied because it was considered a possible intermediary in the process of contamination of the virus from bats to humans.
} 
other groups (Andersen et al., 2020; Li et al., 2020), but none of the studies was conclusive on the relationship between the presence of the virus in pangolins and infection of humans.

The existence of these various possibilities about the virus' origin highlights the uncertainty aspect (from the perspective of the sociology of science) as researchers recognise the impossibility of science providing categorical answers to some of the questions here investigated. Such studies also show other aspects of NOS, such as logic, as new knowledge about the virus was inferred by deduction, based on previous knowledge about other types of coronaviruses (the progressivity aspect).

Although scientists have not identified the specific origin of the virus, they have identified the possibility of natural mutations and recombinations that might lead to its dispersion to humans - which weakens the hypothesis conveyed in some media that the SARS$\mathrm{CoV}-2$ was produced in a laboratory from manipulation of other types of coronavirus (Andersen et al., 2020). This knowledge directly interferes with the speculation that China has produced and spread the virus purposely, or even accidentally, as disseminated in the media at the start of the pandemic (Rincon, 2020). However, the impossibility of identifying the origin of the virus does not allow the possibility that it had been originated in a Chinese laboratory being ruled out (the main suspicion being that this occurred from the Wuhan Institute of Virology (WIV), where several studies about coronaviruses from bats were conducted). While the importance of these studies should be highlighted for the knowledge of how coronavirus contamination occurs from animals to humans, which may help in preventing new pandemics, the carrying out thereof represents a risk of triggering some other pandemic caused by some coronavirus (Rogin, 2020). Considering the possibility that the contamination by SARS-CoV-2 started from strains of virus developed and/or studied at the WIV can lead to thoughts and discussions about ethics, in terms of the risk of conducting this type of research in case of security failure.

This pandemic scenario has led to the development of genetic mapping research worldwide. For example, at the end of February, genetic mapping of virus samples from the first two Brazilian patients diagnosed with COVID-19 was carried out (Toledo, 2020) in just $48 \mathrm{~h}$, which highlights the focus and dedication of scientists to achieve goals (the objectivity aspect). The development of this study was led by two women scientists, which, from the perspective of the anthropology of science, leads to a thought on the role of women in science (the cultural influence aspect). When interviewed by a journalist (Toledo, 2020), one of these scientists mentioned the crucial role of her research funding so that mapping could be done using a quicker and cheaper technique, when compared to other genetic sequencing techniques (the funding source aspect). The protocols used in the sequencing process were developed by a PhD student during a research internship conducted in England, which highlights the importance of interactions among scientists for the generation and enhancement of new knowledge. Last but not least, this study was conducted with the support of the Brazil-United Kingdom Joint Centre, which had mapped epidemics of other diseases (zika and dengue) (Toledo, 2020). Thus, in addition to the interactions among scientists from different nations, we can also highlight the changes in research aims in response to the demand of society in the light of the pandemic (the sociopolitical influence aspect).

Knowledge about the structure of the virus has made it possible to propose prevention measures such as the sanitisation of hands with soap and water and the use of ethanol (60-80\%), which has a great impact on actions to reduce the contagion of the virus. In this regard, we also highlight the actions of scientists to inform the population, using language that is appropriate and, at the same time, close to the colloquial language of ordinary people, as well as simplified models that clearly express ideas (the representation aspect). 
The knowledge about the structure of SARS-CoV-2 also allows us to link it to that of other viruses already known, thereby making it possible to elaborate hypotheses based on knowledge that has already been accepted. By way of example, even before the performance of studies on the behaviour of the SARS-CoV-2, some actions were already taken based on knowledge about the SARS-CoV and MERS viruses (Kampf et al., 2020; Prompetchara et al., 2020; van Doremalen et al., 2020). This is an example of how previously acquired knowledge has a direct influence on how researchers define the paths to be followed in their studies (thus, showing the rationality aspect).

In addition to studies related to the virus' genome and structures, other studies on points such as its stability outside the human body and its power of contagion have aroused great interest from society (the sociopolitical influence aspect), as they have contributed to decisions with regard to measures to mitigate the pandemic. Based on the knowledge that the main form of spreading the virus is by contaminated saliva droplets, several studies have been conducted to identify, for example, the stability of the virus on different surfaces and with different materials (Kampf et al., 2020; van Doremalen et al., 2020); the efficiency of the use of various disinfectants to inactivate the virus (Kampf et al., 2020); the influence of factors such as temperature, air humidity, and air currents in reducing the risk of contagion (Chin et al., 2020); and the development of new methods and technologies to disinfect environments and objects (Gorvett, 2020).

Studies on the spread of the virus in droplets that disperse in the air have led to the proposal of specific guidelines on both physical distancing, and isolation, to restrain the spread of the virus and the consequent contagion, and on measures for the disinfection of surfaces. For example, some studies have shown that a distance of more than $2 \mathrm{~m}$ between people is quite effective in containing contamination (Chu et al., 2020). Other studies, concerning the duration of virus stability on surfaces of different materials, have contributed to the understanding of the potential for contamination as a result of contact with such surfaces (Chin et al., 2020). This has helped with proposing specific care with objects made of distinct materials in their sanitisation and disinfection (the sociopolitical influence aspect).

Other studies on the stability of the SARS-CoV-2 virus, considering environmental factors, have suggested that an increase in temperature (above $70{ }^{\circ} \mathrm{C}$ ) and decreasing air humidity reduce its half-life, which has also helped in the proposition of measures to contain its spread and/or contagion. However, these studies should be carried out under different conditions as the generalisation of the results is not valid for any temperature range, as previously discussed by Kratzel et al. (2020). To predict the half-life of the SARS-CoV-2 virus, mathematical and/or statistical models that take environmental and physical factors into account have been used. For instance, van Doremalen et al. (2020) applied a linear regression model previously used by other scientists in a study of SARS-CoV. This process of studying and investigating the stability of the virus not only shows that science is indeed interdisciplinary but also reflects the aspects of epistemology, because it involves scientific processes in which experiments, inductive and deductive reasoning, and hypothesis design and testing are employed; progressivity, as new knowledge is constructed from previous knowledge; and rationality, as scientists choose specific methods and paths depending on both the objects and the aims of their studies.

Studies have been carried out aiming at developing new materials that could inactivate the virus, thus reducing its spread. One example is the development of tissues that can deactivate the SARS-CoV-2 virus by contact. One of these materials was developed by a Brazilian start-up (Alisson, 2020), from a collaboration between Brazilian and Spanish scientists and a Brazilian research agency (aspect interactions among scientists), who have already applied for the product patent. In the USA, there is now a special fabric that 
inactivates the virus due to a weak electric field generated by microcell batteries (Crowell, 2020). In Israel, a company has developed a fabric coated with nanoparticles of zinc oxide that can also inactivate the SARS-CoV-2 (Reuters, 2020). All these studies involving the application of scientific knowledge to the production of new technologies show mainly the aspects of creativity and applicability. Moreover, in studies concerning the development of new materials, the involvement of companies through financing is common, as they then tend to generate products with great economic potential (the funding source aspect). At the same time, the application for patents of these new materials is an example of competitiveness, as the patent holder shall have the right to economically exploit the knowledge produced.

The development and use of new materials have been driven not only by the current pandemic but also by a view to the future, from the perspective of the economics of science, including the possibility of new outbreaks of other viruses (Roberts, 2020) making the measures to mitigate the spread of the SARS-CoV-2 virus likely to be applied also to contain the spread of other diseases (the applicability aspect).

\subsection{Seeking Solutions to the Problem: The Race to End the Pandemic Through Treatment and Vaccination}

Apart from the mitigation measures to contain the spread and contagion of the SARS$\mathrm{CoV}-2$ as previously mentioned, the great expectation of humanity is the end of the pandemic. In this regard, we can consider two separate fronts: (i) the cure of COVID-19, which assumes that some medicine (or combination of medicines) shall be employed, and (ii) the reduction of the virus contagion by natural immunisation of the population (what has been called herd immunity ${ }^{3}$ ), or mass vaccination.

Among these options, the one least considered in the fight against the pandemic is that of herd immunity because the cost of this action, in terms of lives, may turn out to be very high (Agrela \& Vitorio, 2020; Randolph \& Barreiro, 2020). The forecasts related to herd immunity are based on mathematical models created considering several factors, such as the virus itself and characteristics of the population in which it circulates (mainly in terms of susceptibility of the people when in contact with the virus) (Gomes et al., 2020). Such models are important epistemic tools applied by scientists (within the epistemology aspect) and that, even being derived from mathematical bases and other models widely used in research, can produce distinct results due to subjective choices made by scientists, based on their previous knowledge and methodological choices (part of the subjectivity aspect). Other outcomes of the use of such tools are different ways of representing knowledge, in this case, mainly from graphs of various types (included under the representation aspect).

On the other hand, some of these models' input data concerning the behaviour of the virus in distinct environments and the population's own susceptibility to it are still under investigation. This makes the control of the pandemic based on herd immunity by indiscriminate contamination of the population quite uncertain, which reflects an important aspect of the sociology of science: uncertainty. At the same time, the consideration of a greater number of variables in a model reflects the development of scientists' more complex reasoning (the complexity aspect).

\footnotetext{
${ }^{3}$ Herd immunity occurs when a sufficiently large number of people have already had the disease or been vaccinated, resulting in the acquisition of immunity to the virus. Thus, such people should not be (re) infected and there is a reduction in the spread of the virus in the population (Randolph \& Barreiro, 2020).
} 
In England, initially, the authorities considered adopting herd immunity as a strategy. However, this measure was widely criticised, especially after the results of a survey by the Imperial College London, predicting a high number of deaths during the pandemic (about $510,000)$ and also forecasting that the capacity of hospitals would be exceeded by the second week of April 2020 (Ferguson et al., 2020). The disclosure of the results of this study was decisive for the Prime Minister of the UK to impose a series of restrictions, like the closure of bars, restaurants, gyms, and leisure centres (O'Grady, 2020). In this context, what comes to mind is the ethics aspect together with the aspect of sociopolitical influence because there is a doubt regarding the validity of an immunisation model that could, on the one hand, reduce the risk to more vulnerable people contracting the disease, but, on the other, lead to a higher number of deaths.

Considering that herd immunity from virus infection is far from being an option for tackling the pandemic, there is a rush for drugs and vaccines. In general, both have long protocols for their development, testing, and availability to the population. Thus, a path that can be much shorter is repositioning of drugs, which is the use of medicines for other diseases already approved by the legislators of the countries and with acceptable safety profiles (Kupferschmidt \& Cohen, 2020). In this sense, drugs of two categories were tested: those that act upon the viral replication cycle and those that act upon the symptoms of the disease (Shaffer, 2020). Regardless of the great interest of society in the identification of effective treatments to fight the COVID-19, it is undeniable that the pharmaceutical industries have a great interest in clinical trials involving their drugs and, mainly, on positive outcomes. This reflects the aspect of applicability, as pharmaceutical industries are seeking to sell their medicines worldwide, thus making huge profits (this is the aspect of productivity).

The carrying out of studies on courses of treatment for COVID-19 has had a great impact on society and has generated many discussions. For example, some people have assigned credibility to specific drugs that are still undergoing clinical trials. Among these, perhaps the ones that have triggered the most controversial debates are chloroquine and hydroxychloroquine (medications with similar chemical structures and effects), which have hit the headlines of several newspapers since the pandemic started. Among the first scientists to defend the potential of the use of hydroxychloroquine as treatment for COVID-19 were French microbiologist and infectologist Didier Raoult and his team (Colson et al., 2020a, b). Raoult has a long history in carrying out studies on these drugs, including studies of their use for treatment of malaria and zika (which reflects the aspect of motivational influence of the scientist). Hydroxychloroquine had already shown good in vitro results for the fight against SARS-CoV-2, as discussed in a Chinese study (Gao et al., 2020). However, there are huge differences between in vitro and in vivo tests, as good in vitro results are very common but do not necessarily mean that the drug will have the same effect in living organisms (Andrade \& Sobrinho, 2020). This means that the communication of such results can generate anxiety in people and encourage the use of medicines without scientific bases. The differences between in vitro and in vivo tests results reflect the epistemology aspect, as both are research procedures used in the construction of scientific knowledge.

Regarding in vivo tests, Raoult's team published a study in which the effects of hydroxychloroquine conjugated with azithromycin in patients with COVID-19 were disclosed (Gautret et al., 2020). This study warranted great repercussion in the media, winning over many adherents to the use of this treatment, including the presidents of the USA and Brazil in 2020, who both began to invest in the production of chloroquine and hydroxychloroquine and to publicly defend their use as a way to fight COVID-19. This specific episode stresses many issues associated with aspects of NOS, which go beyond reliability of the 
information. It is linked to the very construction of scientific knowledge, regarding experimental issues, scientific rigour, and acceptability by the scientific community. It also shows that in many cases, even if conveyed by people in authority, information may constitute a reductionist clip and/or lack the necessary scientific basis, and citizens may accept it without batting an eyelid. Also, it concerns with funding source (in this case, from the governments) and sociopolitical influence (considering the involvement of the presidents supporting and even recommending their use, as well as in the denial of scientific knowledge, which jeopardises the acceptance of such knowledge). At the same time, large pharmaceutical companies have donated chloroquine and/or hydroxychloroquine as a way to encourage studies about them and their acceptance, as well as to ensure the consumer market (GlobalData Healthcare, 2020) (which reflects the aspects of applicability and advertising).

The study of Raoult and his team was widely criticised by the academic community, which pointed out several ethical and experimental flaws. For example, (i) the paper was accepted very quickly (the peer review was carried out in less than $24 \mathrm{~h}$ ); (ii) one of the authors is the editor-in-chief of the journal in which the paper was published; and (iii) the approval of an ethics committee for conducting the study was only obtained after the research had been carried out led to questions about ethics in the conduction and communication of the study. The approval of any study involving human beings by a Research Ethics Committee is a mandatory procedure for conducting this type of study, which reflects the epistemology and ethics aspects. The study was also widely criticised for the lack of randomisation, lack of control over the participating groups, and exclusion of data that could impair it (including one death) (Fourcade et al., 2020). This criticism addressed to the process of experimentation is related to subjectivity, given the choices made in the research processes that followed non-explicit forms of logic (which clearly links to the epistemology aspect).

Other aspects that came to the fore about Raoult's works were characteristic of his personality and professional profile. Raoult has a $\mathrm{PhD}$ in microbiology, and many contributions to the field of infectious diseases - an area in which he has published many papers. He is also recognised for his creativity. On the other hand, he is also known for his arrogance, the use of unconventional scientific procedures, the attack on the orthodoxy of science, for questioning and attacking well-established theories, and "for bluster" (Sayare, 2020, para. 2). According to Sayare (2020), "Raoult is reputed to be an indefatigable worker, but he also achieves his extreme rate of publication by attaching his name to nearly every paper that comes out of his institute" (Sayare, 2020, para. 20). Such personal characteristics evidence several aspects of NOS related to the psychology of science, mainly personality (for being dedicated and for bluster), creativity (for designing innovative scientific processes), and subjectivity (for designing unorthodox research methods). Moreover, the fact that his name appears in almost all publications of his institute highlights the aspects of credibility (in which the scientist has his/her prestige and recognition associated with his number of publications) and ethics (because it implies that the scientists take credit for publications in which they may not have contributed intellectually).

Also regarding studies about treatments for COVID-19, it is worth mentioning the Solidarity Study, a coordinated action of interactions among scientists carried out by the WHO, with a pooling of efforts so that reliable scientific results for the treatment for COVID-19 can support guidelines for the population, concerning the pandemic.

One of the courses of treatment participating in this study involves remdesivir, a drug that acts against some families of viruses, including some types of coronavirus (Wang et al., 2020). This drug has an interesting history, being initially produced for the treatment of hepatitis C, but showed no results for this disease. Subsequently, it was tested and used 
in the treatment for other diseases, such as Ebola (Denham et al., 2020). This fact contributes to the discussion about the aspect of fallibility (from sociology of science) since the initial aim for the development of the drug was not achieved, as well as the aspect of nonlinearity, because the initial aim for the production of the drug was changed. Moreover, from epistemology, it is possible to discuss how there is not a single way to produce knowledge.

Another study with remdesivir was carried out by the company that produces it, Gilead Sciences, but the results of the study were not considered statistically significant (Ledford, 2020). Despite this, shortly after the study was published, the US Food and Drug Administration approved the drug to treat patients critically ill with COVID-19, mentioning these results. Then, the US government established a contract to purchase 500,000 courses of treatment involving this medicine, for a value of USD 3120 each (Denham et al., 2020). The investment in this kind of treatment has been criticised, mainly because there was no negotiation to bring down its value, which, according to experts' calculations, could have been reduced to less than 5\% of this (Denham et al., 2020). In addition to the profit from its production of remdesivir, other companies in the world pay fees to Gilead Sciences (the patent holder) to produce the drug. Here, one can observe the aspect of sociopolitical influence, due to the relationships and agreements with the US government, in addition to several other aspects associated with economy of science: access to knowledge, as another company can only produce the drug with the authorisation of the patent holder, and such authorisation only occurs upon payment of fees; applicability, because Gilead Sciences tried to reposition the drug as a treatment for COVID-19; funding source, because there was an investment from the US government and the Gilead Sciences in the initial production of remdesivir; and advertising, from both the results of the studies and the government support for the treatment, stimulating the use of the drug worldwide.

While health systems around the world have been conducting clinical trials on several medicines, more than $85 \%$ of patients infected with SARS-CoV-2 in China were treated with traditional Chinese medicine (Yang et al., 2020). The study carried out by Yang et al. (2020) reviewed publications that analyse the effects of treatments based on traditional Chinese medicine for COVID-19. The application of traditional Chinese medicine highlights the aspect of incommensurability because although there are results of scientific studies that recognise the value of this type of treatment, it is a cultural perspective different from that of Western medicine. That same study stresses the difficulty of objectively evaluating the contributions of such treatments due to problems in the experimental design of the studies, which concerns the epistemology and acceptability aspects.

One of the challenges for drug trials has been that of funding research, as most resources are focused on vaccines. Also, with the promise of rapid development of the latter, the interest of governments and other funding agencies should diminish because the financial return from treatments will be affected once effective vaccines are produced and received by the majority of the population. According to Derek Lowe, a researcher from Duke University in the USA, no medication will bring a 100\% cure for cases of COVID-19 (Dias, 2020). This pessimistic prediction is due to the difficulty inherent to the development of medicines (with a failure rate of about 90\%). More important than this, in order to fight the virus, the ideal situation would be to have the development of specific and totally new drugs, which could take a matter of years, while any vaccine seems to be a closer and more efficient reality (Dias, 2020). Thus, the dispute between the production of medicines and that of vaccines is linked to the aspects of epistemology, given the processes necessary for their production; economic investment and productivity, because the investment of companies and governments in the production of medicines depends on the profit expectations 
and benefits to the population; and tentativeness because, with the advent of vaccines, the drugs may be of little or no importance.

The high expectation concerning the production of vaccines has been largely based on previous knowledge of vaccines against other viruses, or on studies aimed at producing vaccines for the SARS-CoV and MERS. This reflects the aspect of progressivity, to the extent that new knowledge is based on previous knowledge.

At the end of April, a few months after the COVID-19 outbreak was declared a pandemic, over 90 vaccines were being studied in universities and pharmaceutical companies around the world, with over $70 \%$ of such vaccines being produced by private industrial companies (Callaway, 2020). By the end of September, the WHO had registered 169 candidate vaccines, of which 26 were already at the stage of human clinical trials. There is great competitiveness among the pharmaceutical companies that are studying vaccines, not only to produce a vaccine faster but also to produces vaccines that have better immune responses, which maintain the immune response for a longer period. This competitiveness, which will probably result in the production of different vaccines, is good for society as it tends to increase the chances of production of more effective vaccines and favours the speed of production of vaccines in the world, directly interfering with the negotiation of economical values of the vaccines - which may particularly favour poorer nations (the access to knowledge aspect).

A vaccine for COVID-19 can be produced using several approaches to stimulate immunisation. The most frequent are based on the use of weakened or inactivated viruses; other modified viruses that can generate coronavirus proteins; nucleic acid of the virus; and protein fragments or empty virus shells that mimic the outer layer of the coronavirus (Callaway, 2020). The choice of one of these approaches reflects the logic aspect, as this choice supports the production of knowledge based on the expected response of the human body, as well as the progressivity aspect as it considers knowledge previously produced. Other aspects may also have a bearing on the approach used to produce the vaccine, such as motivational influence, when, for instance, a scientist has previous experiences with some kind of approach; subjectivity, with the very way in which distinct scientists may conduct their studies; and creativity, through the need to adopt alternative approaches to the production of new knowledge.

In addition to the initial approach designed to produce vaccines, feasibility should also be evaluated considering, for example, the existence of the necessary technology and the costs of the whole process. In this sense, it seems more advantageous to invest in the manufacture of vaccines for which equipment and technologies are already available, as this also tends to contribute to faster approval by regulatory agencies.

Development of a vaccine is a very long process because it must undergo a three-stage clinical trial process. This process is preceded by a preclinical stage, to analyse if it produces an immune response when tested on cells and given to animals (mainly monkeys, due to them being phylogenetically close to humans). The difficult and expensive access to monkeys tends to bring difficulties to scientists and to affect the execution of some studies (Gryzinski, 2020) (the limitation aspect). In the preclinical stage, it is possible to identify the use of logic, because the tests in species closer to humans aim to contribute to the design and conduction of studies in analogous organisms; ethics, because the need for protocols before human trials seeks to minimise risks to individuals; and economic investment, which relates to the dependence on financial resources for conduction of the studies.

For the success of a vaccine, it is necessary to have the involvement of a large sample in phase 3 of the study, which has helped to bring together research groups from around the world, by recruiting volunteers in several countries. In Brazil, the partnership with 
the Oxford University team proved to be important for the trial and has been important to ensure Brazilians' access to the vaccine. The partnership began from Oxford's lead researcher Andrew Pollard, who contacted the Brazilian researcher Sue Ann Costa Clemens (this being an example of the interactions among scientists aspect), known for conducting research with the recruitment of large numbers of volunteers (the credibility aspect). Sue Ann revealed her firm commitment to establish connections with several research centres in Brazil (the personality aspect), as well as with funding institutions and the federal government (Clemens, 2020) (representing the funding source aspect).

Finally, the possibility of political interference in speeding up the approval of vaccines - as some people feared it could happen before the election for the presidency of the USA (LaFraniere et al., 2020) - has led many pharmaceutical companies to sign an agreement among themselves, stating their public commitment to strictly follow all stages of the clinical trial process. It aims to give society the highest reliability of vaccines (this is the credibility aspect). This commitment highlights the existence of relationships between society and the development of science (this is the aspect of sociopolitical influence) but can also be viewed as an attempt to make sure their products are socially acceptable, related to their interest in making profits (the aspect of productivity).

\subsection{Communication of Produced Knowledge: Scientific Publications During the Pandemic Period}

Given the many publications related to the pandemic and their influence on the knowledge and attitudes of individuals around the world, we have selected the very sources of communication of scientific information as a specific focus for discussing aspects about science.

Within the context of scientific communication, one measure that has been widely adopted is the release of free access to papers related to the pandemic. It was adopted by major publishers around the world, and one of its main consequences is the increased sharing of both research results and their possible multiple interpretations, thus contributing to speed up scientific progress in the area. Another point that has drawn attention is the speed with which papers related to the pandemic have been published (with the whole process often being completed within a few days). This shows that journal editors and reviewers have striven to keep the rigour of the evaluation while speeding up the necessary procedures for peer review and publication. For example, from January to the beginning of May, the number of papers on the topic has doubled every 2 weeks, peaking at over 7000 papers (Speeding up science during the pandemic 2020, para. 1).

The boom in scientific research related to the subject, together with the need for information sharing among researchers all over the world, has led publishers and scientific organisations to focus their efforts on bringing out wide dissemination of research on the subject. In this sense, there have been: (i) specific calls for papers about COVID-19 in journals from several areas; (ii) exemption from fees for submission of papers related to COVID-19 in journals which have fees for submissions; and (iii) prioritisation of reviews of papers addressing the pandemic rather than submissions about other themes. In addition, new mechanisms to speed up the publication process have been adopted. For example, in the journal Nature, the call for rapid sharing of relevant research data on the COVID-19 outbreak has caused an unprecedented increase in preprints (Johansson \& Saderi, 2020), that is, in the availability of papers before being subjected to peer review. As a result, the editors have opted for a process open to the online participation of researchers for the selection of the most relevant preprints, as justified by Johansson and Saderi (2020): 
Outbreaks of pathogens such as the SARS-CoV-2 coronavirus that is responsible for COVID-19 spread and move fast and can affect anyone. Research to support a response to an outbreak needs to be fast and open, too, as do mechanisms to review outbreak-related research. (p. 29)

Thus, the current pandemic has brought marked changes in science, from changes of research foci and researchers' interests to justification of some changes in the way of producing, evaluating, and communicating scientific knowledge. Communication is a key stage within scientific research. Regardless of the media used, it contributes to promotion of both collaboration and debates among scientists as well as universal access to the processes and products of science (whether by scientists or not). Thus, communication is related to the acceptability aspect, while relating to the epistemology itself. Another relevant aspect associated with the whole process of scientific communication is representation because the way of expressing a given element of knowledge can influence its levels of understanding and acceptance. Moreover, scientific communication can foster a broader understanding of NOS, this being the main stage at which scientists disseminate not only their ideas but also the paths trodden, the challenges faced, the funding received, the partnerships established, etc.

The focus of researchers and publishers on scientific production makes explicit the aspect of sociopolitical influence in the production of knowledge, as demand by society leads the scientific community to step up communication, in a move to contribute to solutions to the pandemic. At the same time, the acceleration of the publishing process is related to the progressivity of science, as the published knowledge can be used to support other studies.

The expansion and the quicker speed of availability of scientific publications tend to contribute to access to results from different research groups and, hence, to direct communication and the establishment of partnerships between researchers (representative of the interactions among scientists aspect). However, at the same time when access to information is speeded up, the possibility of decreasing the quality of what is being made available should also be factored in, including possible existence of misleading or more restricted analysed information (Kubota, 2020).

Such changes in the appraisal of papers before making them available to the community are related to the paths used for the production of knowledge, reflecting the aspect of epistemology. At the same time, they relate to the acceptability of scientific knowledge (resulting from the peer review process) and its credibility (due to the relationships between the scientific community and society at large, to the extent that the knowledge produced is used by other scientists or that society recognises the value of that knowledge and defines actions from it). In this sense, when the use of preprints is expanded, the scientific community is expected to help evaluate such papers. It is also expected that, being aware that such studies have not gone through the rigorous process of double-blind review, people will use the information sparingly. On the other hand, the possibility that society as a whole has access to the preprints can lead to misinterpretations of studies, without due consideration of the limitations and possible inconsistencies of what is being communicated. In this sense, one should consider that scientifically literate people can benefit from this access opportunity to the extent that this may favour them when following scientific debates more broadly (considering the limits of what is communicated), as well as to sustain their opinions and decisions more consciously. This can make the paths and processes of science explicit, as highlighted in a report by The Economist magazine: 
In the long run, exposing the messy, argumentative guts of the scientific process could bolster public trust in science itself. Researchers do not follow a straight road to the truth. Rather, they meander, disagree and fumble towards an understanding of the world. In this way all findings are provisional, standing only until later work modifies or overturns them. (Speeding up science during the pandemic 2020, para. 7)

Such considerations show that knowledge of NOS is fundamental to make citizens more critical in relation to scientific publications, especially in the case of preprints. Otherwise, it is likely, for instance, that people who had accessed preprinted data from studies involving drug testing decide to self-medicate or to create magic solutions (representing sociopolitical influence), without understanding possible limitations of such studies (Kubota, 2020).

It is still necessary to know more about the virus, its mutations, its effects on the human body, and the possibilities and effectiveness of different courses of treatment, among many other topics to be explored (aspect uncertainty, from the sociology of science). But it is also necessary that the knowledge produced shall be focused on society, and that the production of new technologies and other actions that improve people's quality of life in this context be stimulated.

The studies cited in this paper constitute only a small sample of how scientific knowledge has been developed by the influence of the pandemic. In the present study, we highlight, mainly, studies related to the virus and its interaction with the human organism. However, studies related to the pandemic are not only those from medical sciences, chemistry, biology, and mathematics - the areas most cited in the media in general. It is necessary to emphasise the carrying out of several studies related to the pandemic and its effects on people and society from human and social sciences. Some examples include those related to topics such as COVID-19 influence on people's mental health (Holmes et al., 2020), on the global economy (Bodrud-Doza et al., 2020; Nicola et al., 2020), on political systems (Kavanagh \& Singh, 2020), and associated with specific ethnic and social contexts (Millett et al., 2020; Price-Haywood et al., 2020; Rimmer, 2020).

Thus, the impact of the pandemic on scientific publications is more intense and broader (as it influences research in many different areas) than pointed out in this paper. However, the clipping was necessary so that we could contemplate the analysis of aspects of NOS that may be of greater interest in science education.

\section{Conclusions and Implications}

Considering the high and accelerated amount of scientific publications in the pandemic period, it is not feasible to exhaustively portray everything that has been produced. In addition to being outside the scope of this paper, one must consider other factors such as the existence of studies that have not yet been published; of studies that, for economic interests, will only be published when their products are closer to being commercialised; and publications in languages other than those we can easily read. However, the current pandemic is a rich socioscientific context in which, as evidenced by our analysis, numerous aspects about science can be made explicit by several publications. The context of the pandemic brings controversial social issues that may support the discussion of NOS, thus fostering scientific literacy (Roberts, 2007). 
Due to the objective narrative of scientific communications, many aspects of NOS are not made explicit, which tend to add weight to a mistaken view of linear and decontextualised science. However, the wide coverage and dissemination of research in progress by newspapers, magazines, and documentaries have contributed widely to people's access to aspects seldom discussed in scientific papers, mainly those related to ethics, personality of scientists, interactions among scientists, and various aspects of the economics of science. For instance, access to content such as interviews with scientists has allowed the identification of their personal involvement, the influence they suffer, and even their dedication to work. This contribution of the media, focusing on different aspects related to the construction of scientific knowledge and different contexts that permeate such construction, was also made evident in Wong et al. (2009).

In this sense, some aspects that help to build a view of science as a dynamic and ongoing process are highlighted in the papers themselves, especially because the pandemic is such a recent topic of research, which implies the existence of many uncertainties in the studies being conducted. Thus, some of the scientific papers highlight the existence of uncertainties, the need for further studies, and the impossibility of reaching conclusions, factors which tend to contribute to a view of science under construction (Latour, 1987).

Due to the role of the media in the communication of knowledge about the pandemic, we emphasise the importance of the discussion on communication in and of science, especially that directed on the public domain. From the present study, we realised that the information provided by different types of media usually includes few details of the study design, without discussing, for instance, aspects related to the reliability or validity of measurements. They may also present unqualified evidence and/or justifications that do not reflect the scientific uncertainties involved. The importance of contributing to functional scientific literacy focused on science communication was previously discussed by Ryder (2001), who identified that such issues need to be understood by students in the field of communication in science.

The different information about scientific studies disseminated by different sources raises the discussion of the importance of scientific literacy involving the media, highlighting the need that science teaching contribute to the development of students' critical reading skills also with respect to the media - which Hodson (2013) names media literacy. In this same perspective, Höttecke and Allchin (2020) articulate the integration of aspects of NOS and socioscientific issues for the promotion of scientific literacy by addressing the development of a broader understanding of NOS in the context of scientific communication (its mediation, the mechanisms involved, and its manipulation), naming it science media literacy.

As discussed by Höttecke and Allchin (2020), twenty-first-century citizens need to develop critical thinking skills and also be able to analyse information from the access and interpretation of different media. Otherwise, they may present distorted views or take biased positions, which may be the product of inadequate communications. Thus, we agree with their view that "students need to understand, mainly holistically, the epistemic structure and provenance of scientific claims that they encounter in everyday life" (Höttecke \& Allchin, 2020, p. 646).

The discussion of aspects of NOS in the socioscientific context of the pandemic may contribute to the promotion of scientific education of students and the general population. This is so because, in view of the sheer mass of information, each individual has opportunities to become aware of such issues, to position themselves, and to act critically, which can contribute to increasing their scientific literacy (Allchin, 2014; Hodson, 2014). For instance, given the information on the efficacy of medicines, it is 
necessary that each citizen seeks to know the origin of such information, whether it is based on scientific studies, what degree of credibility is attributed to such studies, and whether there are political or economic interests in the conduction of the studies, among other aspects of NOS that may contribute to a critical evaluation of the situation. In this sense, knowing distinct contexts and factors that interfere in the production of science, recognising it as a human production, with the limitations and influences inherent in the scientific process, and also understanding the paths and processes for the construction, validation, and communication of scientific knowledge, in addition to other aspects related to NOS (such as those highlighted in this paper concerning the pandemic), are important components of functional scientific literacy (Ryder, 2001).

In this study, the analysis of the knowledge communicated about the pandemic was carried out using categories derived from aspects related to several areas of science, as proposed in the MoSSE v.2 (Santos et al., 2020). To make the study feasible, we restricted our analysis to events and knowledge related to three focus areas: (i) the production and validation of knowledge about the main characteristics of the virus and about controlling the spread of the pandemic; (ii) the production and validation of knowledge about treatments and vaccines; and (iii) the communication of knowledge by different means. Even with such restrictions, the analysis contributed to the identification of a huge range of aspects from all areas of knowledge currently contemplated in the MoSSE v.2. Several of the aspects relate to the same event, thus emphasising the complexity of the relationships that constitute science. Moreover, many other aspects can be identified in the future, or any of the aspects that we identified may be reinterpreted in the future, when relationships that we cannot foresee today may have been revealed. Some aspects get established over time, from a look back that can allow us to see the current situation in a more panoramic way - as we believe it should occur mainly with the area of history of science. Still considering a look back, it seems reasonable to predict that the analysis of the socioscientific issues concerning the COVID19 from aspects associated with areas such as economics, sociology, and anthropology of science may support distinct understanding about science.

In this sense, both the analysis presented here and its possible future modifications point to the potential of the MoSSE v.2 to characterise science and the relationships that constitute it. This analysis consists of a detailed mapping of such characteristics in a contemporary socioscientific case that, due to its complexity and the number of readings required for its broad understanding, perhaps could not be done by science teachers involved in numerous other teaching activities (especially in these days of remote or hybrid activities). Thus, the dissemination of this analysis to teachers may mean a significant contribution to their actions related to planning and conducting creative and motivating teaching situations based on socioscientific issues and focused on teaching about science. Having access to it and knowing the life contexts and interests of their students, teachers can select specific events and/or aspects to support teaching activities that contribute to the promotion of their functional scientific literacy.

Finally, possibilities to increase relevant knowledge in science education may come from conducting empirical studies aimed at (i) students and teachers' learning in such teaching contexts, and (ii) possible developments of teachers' knowledge resulting from their experiences of using the MoSSE v. 2 in other contemporary socioscientific cases that, like the one related to COVID-19, may support students' access to issues concerning science under construction. 
Acknowledgements We thank Dr. Stefannie Ibraim for her insightful comments on the draft version of the paper, and our financial sponsors: Conselho Nacional de Desenvolvimento Científico e Tecnológico, CNPq, and Coordenação de Aperfeiçoamento de Pessoal de Nível Superior, CAPES.

Funding Partial financial support was received from Conselho Nacional de Desenvolvimento Científico e Tecnológico, CNPq, Brazil (Grant number 306638/2016-9), and Coordenação de Aperfeiçoamento de Pessoal de Nível Superior, CAPES, Brazil (Finance Code 001).

\section{Declarations}

Conflict of Interests All authors declare that they have no competing interests.

\section{References}

Agrela, L., \& Vitorio, T. (2020). Todos contaminados por covid-19? O risco da imunidade de rebanho [Everybody contaminated by Covid-19? The risk of herd immunity]. Exame.

Aikenhead, G. S. (2006). Science education for everyday life: Evidence-based practice. Teachers College Press.

Alisson, E. (2020). Empresa paulista desenvolve tecido capaz de eliminar o novo coronavírus por contato [A company of São Paulo city develops a tissue capable of eliminating the new coronavirus by contact]. Agência FAPESP.

Allchin, D. (2011). Evaluating knowledge of the nature of (whole) science. Science Education, 95(3), 518542. https://doi.org/10.1002/sce.20432

Allchin, D. (2014). From science studies to scientific literacy: A view from the classroom. Science \& Education, 23(9), 1911-1932. https://doi.org/10.1007/s11191-013-9672-8

Andersen, K. G., Rambaut, A., Lipkin, W. I., Holmes, E. C., \& Garry, R. F. (2020). The proximal origin of SARS-CoV-2. Nature Medicine, 26(4), 450-452.

Andrade, H. D., \& Sobrinho, W. P. (2020). COVID-19: "Teste de remédio in vitro não significa que funciona em humano" [Covid-19: "In vitro drug testing does not mean it works on humans"]. UOL.

Bodrud-Doza, M., Shammi, M., Bahlman, L., Islam, A. R. M., \& Rahman, M. (2020). Psychosocial and socio-economic crisis in Bangladesh due to COVID-19 pandemic: A perception-based assessment. Frontiers in Public Health, 8, 341. https://doi.org/10.3389/fpubh.2020.00341

Callaway, E. (2020). The race for coronavirus vaccines: A graphical guide. Nature, 580(7805), 576-577. https://doi.org/10.1038/d41586-020-01221-y

Capps, D. K., \& Crawford, B. A. (2013). Inquiry-based professional development: What does it take to support teachers in learning about inquiry and nature of science? International Journal of Science Education, 35(12), 1947-1978. https://doi.org/10.1080/09500693.2012.760209

Chin, A., Chu, J., Perera, M., Hui, K., Yen, H.-L., Chan, M., et al. (2020). Stability of SARS-CoV-2 in different environmental conditions. The Lancet Microbe, 1(1), e10. https://doi.org/10.1016/S26665247(20)30003-3

Chu, D. K., Akl, E. A., Duda, S., Solo, K., Yaacoub, S., Schünemann, H. J., et al. (2020). Physical distancing, face masks, and eye protection to prevent person-to-person transmission of SARS-CoV-2 and COVID-19: A systematic review and meta-analysis. The Lancet, 395(10242), 1973-1987. https://doi. org/10.1016/S0140-6736(20)31142-9

Clemens, S. A. C. (2020). 'Lutei como uma leoa para trazer a pesquisa' ['I fought like a lioness to bring the research']. $O$ Estado de São Paulo.

Colson, P., Rolain, J.-M., Lagier, J.-C., Brouqui, P., \& Raoult, D. (2020a). Chloroquine and hydroxychloroquine as available weapons to fight COVID-19. International Journal of Antimicrobial Agents, 55(4), 105932. https://doi.org/10.1016/j.ijantimicag.2020.105932

Colson, P., Rolain, J.-M., \& Raoult, D. (2020b). Chloroquine for the 2019 novel coronavirus SARS-CoV-2. International Journal of Antimicrobial Agents, 55(3), 105923. https://doi.org/10.1016/j.ijantimicag. 2020.105923

Crowell, R. (2020). Roupas e máscaras feitas com novo tecido elétrico poderiam matar o coronavírus [Clothes and masks made with a new electric tissue can kill coronavirus]. Scientific American Brazil.

Denham, H., Abutaleb, Y., \& Rowland, C. (2020). Gilead sets price of coronavirus drug remdesivir at $\$ 3,120$ as Trump administration secures supply for 500,000 patients. The Washington Post. 
Dias, M. (2020). Nenhum remédio será cura para Covid-19; esperança é a vacina, diz cientista [Any medicine will be the cure for Covid-19, the hope is the vaccine, says scientist]. Folha de São Paulo.

Ferguson, N. M., Laydon, D., Nedjati-Gilani, G., Imai, N., Ainslie, K., Baguelin, Marc, et al. (2020). Report 9: Impact of non-pharmaceutical interventions (NPIs) to reduce COVID-19 mortality and healthcare demand. London: Imperial College COVID-19 Response Team, Imperial College.

Fourcade, M., Kresge, N., \& Nussbaum, A. (2020). French researcher who pushed HCQ for COVID-19 is caught in hope vs hype controversy. The Print.

Gao, J., Tian, Z., \& Yang, X. (2020). Breakthrough: Chloroquine phosphate has shown apparent efficacy in treatment of COVID-19 associated pneumonia in clinical studies. Bioscience Trends, 14, 172-73. https://doi.org/10.5582/bst.2020.01047

Gautret, P., Lagier, J.-C., Parola, P., Meddeb, L., Mailhe, M., Doudier, B., et al. (2020). Hydroxychloroquine and azithromycin as a treatment of COVID-19: Results of an open-label non-randomized clinical trial. International Journal of Antimicrobial Agents, 56(1), 105949. https://doi.org/10.1016/j.ijantimicag. 2020.105949

GlobalData Healthcare (2020). The impact of big pharma on COVID-19. Pharmaceutical Technology.

Gomes, M. G. M., Aguas, R., Corder, R. M., King, J. G., Langwig, K. E., Souto-Maior, C., et al. (2020). Individual variation in susceptibility or exposure to SARS-CoV-2 lowers the herd immunity threshold. medRxiv. https://doi.org/10.1101/2020.04.27.20081893 [Preprint].

Gorvett, Z. (2020). Can you kill coronavirus with UV light? BBC Future.

Gryzinski, V. (2020). Na era do novo vírus, quanto custa um macaco de laboratório? [In the virus era, how expensive is a lab monkey?]. Veja.

Hanuscin, D. L., Akerson, V. L., \& Philipson-Mower, T. (2006). Integrating nature of science instruction into a physical science content course for preservice elementary teachers: Nos views of teaching assistants. Science Education, 90(5), 912-935. https://doi.org/10.1002/sce.20149

Hodson, D. (2013). Don't be nervous, don't be flustered, don't be scared. Be prepared. Canadian Journal of Science, Mathematics and Technology Education, 13(4), 313-331. https://doi.org/10.1080/14926156. 2013.845327

Hodson, D. (2014). Learning Science, learning about science, doing science: Different goals demand different learning methods. International Journal of Science Education, 36(15), 2534-2553. https://doi.org/ 10.1007/s11191-011-9368-x

Holmes, E. A., O’Connor, R. C., Perry, V. H., Tracey, I., Wessely, S., Arseneault, L., et al. (2020). Multidisciplinary research priorities for the COVID-19 pandemic: A call for action for mental health science. The Lancet Psychiatry, 7, 547-560. https://doi.org/10.1016/S2215-0366(20)30168-1

Höttecke, D., \& Allchin, D. (2020). Reconceptualizing nature-of-science education in the age of social media. Science Education, 104, 641-666. https://doi.org/10.1002/sce.21575

Johansson, M. A., \& Saderi, D. (2020). Open peer review for COVID-19 preprints. Nature, 579, 29. https:// doi.org/10.1038/d41586-020-00613-4

Justi, R., \& Erduran, S. (2015). Characterizing nature of science: A supporting model for teachers. Paper presented at the Paper presented at the Conference of the International History, Philosophy, and Science Teaching Group, Rio de Janeiro, Brazil.

Kampf, G., Todt, D., Pfaender, S., \& Steinmann, E. (2020). Persistence of coronaviruses on inanimate surfaces and their inactivation with biocidal agents. Journal of Hospital Infection, 104(3), 246-251. https://doi.org/10.1016/j.jhin.2020.01.022

Karimi, N., \& Gambrell, J. (2020). Industrial alcohol coronavirus 'cure' kills hundreds of Iranians. New York Daily News.

Kavanagh, M. M., \& Singh, R. (2020). Democracy, capacity, and coercion in pandemic response - COVID 19 in comparative political perspective. Journal of Health Politics, Policy and Law, 45, 997-1012. https://doi.org/10.1215/03616878-8641530

Kratzel, A., Steiner, S., Todt, D., V'kovski, P., Brueggemann, Y., Steinmann, J., et al. (2020). Temperaturedependent surface stability of SARS-CoV-2. Journal of Infection, 81(3), 452-482. https://doi.org/10. 1016/j.jinf.2020.05.074

Kubota, T. (2020). Stanford researchers discuss the benefits - and perils - of science without peer review. Stanford News: Stanford Unversity Comunications.

Kumar, S., Nyodu, R., Maurya, V. K., \& Saxena, S. K. (2020). Morphology, genome organization, replication, and pathogenesis of severe acute respiratory syndrome coronavirus 2 (SARS-CoV-2). In S. K. Saxena (Ed.), Medical Virology: From Pathogenesis to Disease Control. (pp. 22-31). Springer.

Kupferschmidt, K., \& Cohen, J. (2020). Race to find COVID-19 treatments accelerates. Science, 367(6485), 1412-1413. https://doi.org/10.1126/science.367.6485.1412

LaFraniere, S., Thomas, K., Weilan, N., Baker, P., \& Karni, A. (2020). Scientists worry about political influence over coronavirus vaccine project. The New York Times. 
Lam, T.T.-Y., Shum, M.H.-H., Zhu, H.-C., Tong, Y.-G., Ni, X.-B., Liao, Y.-S., et al. (2020). Identifying SARS-CoV-2 related coronaviruses in Malayan pangolins. Nature, 583, 282-285. https://doi.org/ 10.1038/s41586-020-2169-0

Latour, B. (1987). Science in action. Harvard University Press.

Ledford, H. (2020). Coronavirus breakthrough: Dexamethasone is first drug shown to save lives. Nature, 582(7813), 469. https://doi.org/10.1038/d41586-020-01824-5

Li, X., Giorgi, E. E., Marichannegowda, M. H., Foley, B., Xiao, C., Kong, X.-P., et al. (2020). Emergence of SARS-CoV-2 through recombination and strong purifying selection. Science Advances, 6(27), eabb9153. https://doi.org/10.1126/sciadv.abb9153

Loughran, J. (2011). Responding to the challenge of scientific literacy: A whole school approach to scientific literacy. In J. Loughran, K. Smith, \& A. Berry (Eds.), Scientific literacy under the microscope: A whole school approach to science teaching and learning. (Vol. 11) Springer Science.

Lu, R., Zhao, X., Li, J., Niu, P., Yang, B., Wu, H., et al. (2020). Genomic characterisation and epidemiology of 2019 novel coronavirus: Implications for virus origins and receptor binding. The Lancet, 395(10224), 565-574. https://doi.org/10.1016/S0140-6736(20)30251-8

Millett, G. A., Jones, A. T., Benkeser, D., Baral, S., Mercer, L., Beyrer, C., et al. (2020). Assessing differential impacts of COVID-19 on Black communities. Annals of Epidemiology, 47, 37-44.

Nicola, M., Alsafi, Z., Sohrabi, C., Kerwan, A., Al-Jabir, A., Iosifidis, C., et al. (2020). The socio-economic implications of the coronavirus and COVID-19 pandemic: A review. International Journal of Surgery, 78, 185-193. https://doi.org/10.1016/j.ijsu.2020.04.018

Nuwer, R. (2020). Illegal trade in pangolins keeps growing as criminal netwoks expand. National Geographic.

O'Grady, C. (2020). The U.K. backed off on herd immunity. To beat COVID-19, we'll ultimately need it. National Geographic.

Price-Haywood, E. G., Burton, J., Fort, D., \& Seoane, L. (2020). Hospitalization and mortality among black patients and white patients with COVID-19. New England Journal of Medicine, 382, 25342543. https://doi.org/10.1056/NEJMsa2011686

Prompetchara, E., Ketloy, C., \& Palaga, T. (2020). Immune responses in COVID-19 and potential vaccines: Lessons learned from SARS and MERS epidemic. Asian Pacific Journal of Allergy and Immunology, 38(1), 1-9. https://doi.org/10.12932/AP-200220-0772

Randolph, H. E., \& Barreiro, L. B. (2020). Herd immunity: Understanding COVID-19. Immunity, 52(5), 737-741. https://doi.org/10.1016/j.immuni.2020.04.012

Reuters (2020). Israeli mask maker Sonovia expects $99 \%$ coronavirus success after lab test. The Jerusalem Post.

Rimmer, A. (2020). COVID-19: Disproportionate impact on ethnic minority healthcare workers will be explored by government. British Medical Journal, 369, m1562. https://doi.org/10.1136/bmj.m1562

Rincon, P. (2020). Coronavírus: há alguma evidência de que o sars-cov-2 tenha sido criado em laboratório? [Coronavirus: Is there any evidence that sars-cov-2 was created in laboratory?]. BBC News.

Roberts, D. A. (2007). Scientific literacy/science literacy. In S. K. Abell \& N. G. Lederman (Eds.), Handbook of research on science teaching. (pp. 729-780). Routledge.

Roberts, M. (2020). Flu virus with 'pandemic potential' found in China. BBC News.

Rogin, J. (2020). State Department cables warned of safety issues at Wuhan lab studying bat coronaviruses. Washington Post.

Ryder, J. (2001). Identifying science understanding for functional scientific literacy. Studies in Science Education, 36(1), 1-44. https://doi.org/10.1080/03057260108560166

Sadler, T. D. (2011). Situating socio-scientific issues in classrooms as a means of achieving goals of science education. In T. D. Sadler (Ed.), Socio-scientific Issues in the Classroom. (pp. 1-9). Springer.

Sadler, T. D., Chambers, F. W., \& Zeidler, D. L. (2004). Student conceptualizations of the nature of science in response to a socioscientific issue. International Journal of Science Education, 26(4), 387-409

Santos, M., Maia, P., \& Justi, R. (2020). A model of science to base the introduction of aspects of nature of science in teaching contexts and to analyse such contexts. Revista Brasileira de Pesquisa em Educação em Ciências, 20, 617-651. https://doi.org/10.28976/1984-2686rbpec2020u617651

Sayare, S. (2020). He was a science star. Then he promoted a questionable cure for COVID-19. The New York Times.

Shaffer, L. (2020). 15 drugs being tested to treat COVID-19 and how they would work. Nature medicine: Feature News.https://doi.org/10.1038/d41591-020-00019-9.

Speeding up science during the pandemic. (2020). The Economist.

Toledo, K. (2020). Sequenciamento identifica genomas diferentes nos dois casos brasileiros de coronavirus [Sequencing identifies different genomes in the two Brazilian cases of coronavirus]. Agência Fapesp. 
van Doremalen, N., Bushmaker, T., Morris, D. H., Holbrook, M. G., Gamble, A., Williamson, B. N., et al. (2020). Aerosol and surface stability of SARS-CoV-2 as compared with SARS-CoV-1. The New England Journal of Medicine, 382(16), 1564-1567. https://doi.org/10.1056/NEJMc2004973

Wang, Y., Zhang, D., Du, G., Du, R., Zhao, J., Jin, Y., et al. (2020). Remdesivir in adults with severe COVID-19: a randomised, double-blind, placebo-controlled, multicentre trial. The Lancet, 395(10236), 1569-1578. https://doi.org/10.1016/S0140-6736(20)31022-9

Wong, S. L., Kwan, J., Hodson, D., \& Yung, B. H. W. (2009). Turning crisis into opportunity: Nature of science and scientific inquiry as illustrated in the scientific research on severe acute respiratory syndrome. Science \& Education, 18(1), 95-118. https://doi.org/10.1007/s11191-007-9123-5

Wong, S. L., Wan, Z., \& Cheng, M. M. W. (2011). Learning nature of science through socioscientific issues. In T. D. Sadler (Ed.), Socio-scientific issues in the classroom. (pp. 245-269). Springer.

Wu, F., Zhao, S., Yu, B., Chen, Y.-M., Wang, W., Song, Z.-G., et al. (2020). A new coronavirus associated with human respiratory disease in China. Nature, 579(7798), 265-269. https://doi.org/10.1038/ s41586-020-2008-3

Yang, Y., Islam, M. S., Wang, J., Li, Y., \& Chen, X. (2020). Traditional Chinese medicine in the treatment of patients infected with 2019-new coronavirus (SARS-CoV-2): A review and perspective. International Journal of Biological Sciences, 16(10), 1708. https://doi.org/10.7150/ijbs.45538

Zeidler, D. L., \& Nichols, B. H. (2009). Socioscientific issues: Theory and practice. Journal of Elementary Science Education, 21(2), 49. https://doi.org/10.1007/BF03173684

Zhou, P., Yang, X.-L., Wang, X.-G., Hu, B., Zhang, L., Zhang, W., et al. (2020). A pneumonia outbreak associated with a new coronavirus of probable bat origin. Nature, 579(7798), 270-273. https://doi.org/ $10.1038 / \mathrm{s} 41586-020-2012-7$

Publisher's Note Springer Nature remains neutral with regard to jurisdictional claims in published maps and institutional affiliations. 